Journal of Qualitative Criminal Justice \& Criminology

\title{
Conceptualizing Social
}

\section{Recovery: Recovery Routes}

of Methamphetamine

Users

Miriam Boeri $^{1}$, David Gibson ${ }^{2}$, Paul Boshears ${ }^{3}$

${ }^{1}$ Bentley University, ${ }^{2}$ Kennesaw State University, ${ }^{3}$ The European Graduate School

Published on: Apr 01, 2014

DOI: $10.21428 / 88 d e 04 a 1 . c e 2 a 8386$

License: Creative Commons Attribution 4.0 International License (CC-BY 4.0). 


\section{ABSTRACT}

The goal of our qualitative study was to gain a phenomenological understanding of routes to recovery from problematic drug use. In-depth interviews and drug histories were collected from 50 former methamphetamine users recruited from a U.S. metropolitan suburb who identified as having had problematic use of this drug in the past. Transcripts of the audio-recorded interviews were coded for common themes regarding types of recovery strategies or tools employed on the route to recovery. The common strategies used in all routes for recovery from problematic methamphetamine use were social in nature and did not necessarily include the cessation of all substances. Based on our findings, we suggest a conceptualization of social recovery that focuses on reducing the social harms caused by problematic drug use rather than focusing primarily on cessation of all drug use. Social recovery may be employed as both a treatment strategy and analytical tool. More research is needed to advance the concept of social recovery for intervention, drug policy, and criminal justice implications.

\section{Introduction}

In this article, we examine the routes to recovery recounted by former methamphetamine users who spoke of past use as being problematic; they typically used the term addiction. We begin by defining the terms used and reasons for employing these terms. Addiction has been called a "troublesome concept" (Akers, 1991) that can indicate a range of compulsive modes of drug use (Bailey, 2005; Cloud \& Granfield, 2008; Granfield, 2004; Weinberg, 2000). The concept of addiction also "invites us to apply a rational/decision making framework to our fellow men/women, up to the point where they start to encounter problems with their drug use, and then to switch to a view of man/woman as machine" (Davies, 1998, p. 268). There is a fundamental dilemma with attributing both agency and automation to the process of becoming addicted. The term problematic use provides a more succinct understanding for the purposes of this exploration on recovery (Reinarman, 2005). Our aim is to identify common strategies used in diverse routes to recovery from problematic drug use, in this study specifically, the problematic use of methamphetamine.

While there is no consensus on its definition, the term recovery is often used to indicate total abstinence of alcohol and drug use, particularly in 12-step literature where the process of maintaining abstinence is referred to as being in recovery or a recovering user (Granfield \& Cloud, 1999; Hoffman, 2003; Laudet, 2007; Laudet \& White, 2008). In some cases, the term recovery is employed to indicate the cessation of problematic drug use but not necessarily all of alcohol and drug use (Barker \& Hunt, 2007; Weinberg, 2000). An example of this is when a methamphetamine user stops using methamphetamine but still drinks alcoholic beverages or smokes marijuana. In this article, recovery indicates cessation of methamphetamine but not necessarily the abstinence of substance use that is not problematic. To distinguish between legal and illegal drugs, we use the term drug when referring 
to illicit drug use only and the term substance when referring to both illicit and/or licit substances such as alcohol.

In this paper, routes are defined as pathways taken to achieve desired recovery goals. Strategies are defined as any method, behavior, action or tool that helps achieve cessation of problematic drug use. These terms are further examined in our review of the literature, and our reasons for distinguishing them are explained in the analysis discussion.

The term former user is employed ambiguously in drug use literature since former user implies that the drug will never be used again; yet we know that recovery often involves multiple relapses and reattempts at cessation of problematic drug use (Laudet \& White, 2008; Mitchell et al., 2011; Scott, Foss, $\&$ Dennis, 2005). Since relapse is so common along the route to recovery, a former user status should be qualified. Developed by researchers, categories of former users are often distinguished between those who have recently ceased use, those with one year of abstinence, and those with long-term cessation. For example, stable recovery is defined as at least five years of remission (Cloud \& Granfield, 2001), while sustained recovery is defined as abstinence of any drug use over one year (Laudet \& White, 2008). We can know by a user's self-report when a drug was last used, so we can state that a user is inactive for a certain period of time. Since the term inactive user seems contradictory, we continue to use the term former user with the understanding that this is a known current status that has endured for a certain period of time. In this research, we analyze the data of all former users who have not used methamphetamine in the past month. This sample of former users includes a subset of those in stable recovery.

Few studies have been conducted to qualitatively analyze former users' narratives to understand all routes and strategies used along the pathway to recovery from their perspectives. Typically, standard measures of addiction and recovery are employed with survey data or textual data using quantitative analysis which can miss the nuanced meanings of what recovery means and the variances of recovery strategies over time. Here, we employ a phenomenological perspective to gain in-depth understanding of the recovery process from the insiders' experiences. The process of recovery is important for drug treatment as well as for criminal justice professionals, since drug use is illegal and is often addressed by incarceration. In recent years, a growing prison population has increased the number of inmates provided drug treatment under the supervision of the criminal justice system, both inside and outside prison facilities (Belenko, 1999; Boeri, Lamonica, \& Harbry, 2011; Deschenes, Ireland, \& Kleinpeter, 2009; Lyons, 2010; Nolan, 2003). A better understanding of diverse strategies employed to prevent problematic drug use and relapse is important for crime control.

\section{Background}




\section{Routes to recovery}

The two most commonly discussed routes to recovery are treatment and self-help groups that follow the 12-step model (hereafter referred to as 12-step). Discussions of routes to recovery typically employ an individualistic etiology with an emphasis on changing characteristics of the individual (Graham, Young, valach, \& Wood, 2008; Hammersley \& Reid, 2002). When based on contemporary models of recovery, programs are often value-laden with psychological or biological implications. For example, the disease model incorporates the use of treatment medication, usually to counteract withdrawal symptoms, with a variety of behavioral therapies (Bischof, Rumpf, Meyer, Hapke \& Ulrich, 2007; Dole \& Nyswander, 1965; Kaufman \& Poulin, 1996). Legal definitions of illicit drugs also drive our current conceptualization of recovery. Individuals with substance use problems often seek or are mandated (by courts or family) to participate in drug treatment. While a comprehensive treatment program might include cognitive behavioral therapies and social learning skills for the individual, the social aspects of the recovery process are normally limited to participation in 12-step during the treatment program or recommended as an aftercare plan to avoid relapse (Laudet, 2008; Nolan, 2003).

The 12-step model is one of the most ubiquitous programs used in the criminal justice system or by exoffenders under probation or parole supervision (Ross \& Richards, 2002; 2009). The ontological formulation employed by 12-step philosophy is the omnipresent risk of relapse that is pronounced in the adage, "once an addict, always an addict." The 12-step model also proscribes normative behavior for recovering users that is highly monitored through social control (Alcoholic Anonymous [1952] 1981; Pollner \& Stein, 1996). Although research on the success of 12-step shows mixed results (Emrick, Tonigan, Montgomery, \& Little, 1993; Peele, 1989), the efficacy of these programs seems to be based on the sociological insight that users who change not only their individual behaviors but also their social context are more likely to abstain from substance use.

One of the only conventional recovery models to use a substitute drug is the methadone maintenance plan (also known as opiate substitute program), a route to recovery typically employed by users of narcotics seeking treatment; this program has been shown to be successful (Fischer, Rehm, Kim, \& Kirst, 2005). The use of a substitute drug or prescription medication is rarely employed in treatment for methamphetamine, although research shows that prescribing amphetamines as part of a methamphetamine treatment plane relieves the withdrawal symptoms, increases treatment retention, and reduces the frequency of drug use (McBride, Sullivan, Blewett, \& Morgan, 1997; Stewart \& Brown, 1995).

A third route to recovery that is less discussed in recent treatment literature is natural recovery (Biernacki, 1986; Waldorf, 1983), also called selfchange (Barker \& Hunt, 2007; Sobell, 2007). 1 Natural recovery has been studied periodically but has had difficulty achieving sustained research focus, although recently it is being studied as self-change (Klingemann, 2011). According to Biernacki (1986), 
natural recovery requires forming a new identity that corresponded to new perspectives, such as may occur in religious conversion. A different discussion of natural recovery focused on social contexts and the relational aspects of recovery (Granfield \& Cloud, 1996).

\section{Social capital}

The conceptual lens of social capital can provide insight into the nature of cessation of problematic drug use by foregrounding the social bonding within a recovering network and the change in social capital that might occur during the recovery process (Cloud \& Granfield, 2008; Schuller, 2007). Social capital refers to "the social norms and networks that enhance people's ability to collaborate on common endeavors" (Putnam, 2000, p. 35). The concept has been widely used to explain the unequal distribution of social resources available to individuals within their communities and across social networks that act as a barrier to obtaining desired goals (Bourdieu, 1984; Coleman, 1988).

Richard Granfield and William Cloud (2001), noting a direct correlation between social capital and recovery, coined the term recovery capital and defined it as the combined physical resources, skills, knowledge, and social capital available to a recovering person. Strategies used to increase recovery capital include engaging in alternatives to drug use, creating new relationships to take the place of old drug relationships, and avoiding triggers (Cloud \& Granfield 2001; Granfield \& Cloud, 1999).

While recovery capital is used to predict sustained recovery, its analytical lens remains focused primarily on the actions and behaviors of the individual user. The findings of a study evaluating recovery capital measures found that "only 12-step involvement and life meaning emerged as significant predictors of sustained recovery" (Laudet \& White, 2008, p. 35). Both being involved in a group and acquiring meaning in life are very individualistic characteristics that again turn the analytical lens on an individual's accountability. Moreover, while the bonding aspects of social capital are intensely measured by recovery capital, the bridging characteristics of social capital are largely overlooked.

The relationship between the individual, community resources, and resources available from connections outside one's social network are part of social capital. Arguing that analysis should not center on individuals, groups or communities, but more specifically on the relations between and among them, Tom Schuller (2007) proposed moving beyond social networks by focusing on the process involved in acquiring or losing social capital. Instead, a social capital analysis should include not merely membership in a social network but what the network means, how embedded it is, how it functions, and the individual relations in this network and other networks. To this end, Schuller proposed a typology to consider the various relationships that exist between social networks along the dimensions of bonding and bridging social capital. Bonding social capital is defined as "the links with others who are broadly similar in kind," and bridging social capital as "the links a community has with others that 
are different" (p. 15). Although high bridging with little bonding alienates individuals, a very tight bonding mechanism in a social network may be detrimental if there is a lack of bridging, resulting in the dark side of social capital-an exclusionary community. Both bonding and bridging mechanisms are critical for drug users seeking recovery.

While traditional treatment and 12-step groups appear to work for many individuals, the wellsupported findings of high relapse rates call for more research that extends its lens beyond contemporary options (Hammersley \& Reid, 2002; Klingemann \& Klingemann, 2007; Scott et al., 2005). Studies show that given the diversity of types of substance users, a diversity of types of recovery strategies are also needed (Barrick \& Conners, 2002; Hubbard, Flynn, Craddock, \& Platt, 2001; Sexton, Carlson, Leukefeld, \& Booth, 2008). Moreover, very few people who need treatment for substance use actually seek treatment, and many who do seek treatment may not find one strategy appropriate for their needs but instead use multiple strategies (SAMHSA, 2008). To better understand what is called the treatment gap (NIDA, 2009), further research needs to be done to investigate the various strategies employed by those who do not use traditional treatment or 12-step programs.

\section{Social recovery}

Our concept of social recovery directs attention to the social environment with a primary focus on human interaction (Boeri, Lamonica, \& Harbry, 2011). Social recovery emphasizes the process of recovering socially rather than the abstinence from all substances. While recovery capital refers to the combined physical resources, skills, knowledge, and social capital available to a recovering person (Granfield \& Cloud, 2001), social recovery refers to the process of acquiring the skills, resources, and networks needed that enhance people's ability to live in society without resorting to problematic substance use (Boeri, 2013; Boshears, Boeri, \& Harbry, 2011). In sum, our conceptualization of social recovery is different from the current development of recovery capital in that it focuses less on individual actions and more on social interactions, acknowledging that social bonding and bridging relationships outside treatment or self-help groups can also lead to measurable success.

While not often used in addiction literature, the term social recovery is employed in mental health treatment such as social recovery-oriented cognitive behavioral therapy for people diagnosed with psychosis (Barton et al., 2009). Social recovery also is employed in medical treatment, such as after hip replacement surgery or head injuries (Grant, St. John, \& Patterson, 2009; Kunishio et al., 1993). In these situations, social recovery is used to emphasize the social aspects of achieving the desired outcome of adequate mental or physical health status. We found only a few mentions of social recovery in drug treatment literature, all of which referred to social relationships promoted within a treatment program that included 12-step models (Kelly, Brown, Abrantes, Kahler, \& Myers, 2008; Weinberg, 2005). In these contexts, social recovery is used as a measurable outcome, much like recovery capital is employed. For example, in the literature, recovery capital is measured by social 
activities that are highly controlled by other 12-step members (Laudet, 2008; Kelly et al., 2008; Weinberg, 2005). In contrast, for most of the time spent outside treatment, the practice of recovery can be seen as negotiating life within an environment where drug or alcohol use may be prevalent. Diverting our focus away from the act of drug use and instead placing it on the users' social life reveals new narratives of recovery. Social recovery, as it emerged in our analysis, is an inclusive conceptualization that favors a harm reduction approach to ameliorating the social aspects of problematic drug use, for example, through social relations and social roles that increase social capital (Cheung \& Cheung, 2003).

Drawing on a harm reduction and stepped-care approach (Moore, 2005), we do not use recovery to indicate cessation of all substance use. Rather, we use recovery to indicate cessation of problematic drug use (here methamphetamine) and not necessarily of all drugs. Research shows that polydrug use or sequential use of different drugs are common patterns, and drug use modulation may be considered beneficial in some settings (Bletzer, 2009; Lamonica \& Boeri, 2012). Our aim in this article is to examine all recovery processes to identify common patterns in the strategies employed to cease problematic use. The narratives of individuals who identified as former methamphetamine users provide a phenomenological understanding of routes and strategies to recovery.

\section{Methods}

The data for our analysis were drawn from a larger qualitative study of methamphetamine users in the suburbs of a southeastern U.S. metropolis. These suburbs were identified as one of the areas in the U.S. most affected by the rapid increase in methamphetamine use (NIDA, 2006).

Methamphetamine is a stimulant similar to the chemical structure of prescription amphetamines and can be smoked, snorted, taken intravenously, or ingested either orally or rectally. It affects the central nervous system and releases dopamine neurotransmitters to the brain while simultaneously inhibiting their uptake, producing a pleasurable experience along with increased activity and decreased appetite (Logan, 2002).

We employed qualitative methods and ethnographic strategies. Preliminary fieldwork entailed becoming familiar with local drug scenes and building rapport with key actors in these scenes. This involved hanging out for repeated and extended periods of time in places where people congregate, such as bars, coffee houses, suburban neighborhood streets, shopping centers, public Laundromats, and all-night restaurants. We identified specific research spots in diverse areas through the help of community consultants -individuals recruited in the field who have inside knowledge of methamphetamine use in the area due to their own use or former use (Gorman, Morgan, \& Lambert, 1995). In addition to using targeted and snowball sampling methods to recruit respondents for interviews (Strauss \& Corbin, 1998; Watters \& Biernacki, 1989), we also posted fliers in strategic places advertising a confidential research study with a phone number and passed out our business cards that 
discretely reminded people we met while in the field to call our number. Our non-judgmental attitude and acts of kindness, such as offering rides to the store, helped us to build trust and rapport with our study population.

The research team consisted of trained ethnographers who conducted fieldwork, interviews, and coding of the qualitative data, including in-depth field notes describing the scenes and conversations with the study population and transcripts of audio-recorded interviews with study respondents. To be eligible to participate in the study, the participants had to be 18 or older and had used methamphetamine in the suburbs. We focused enrollment to achieve $50 \%$ active and $50 \%$ former users. Active users were defined as having used methamphetamine at least one time in the past month. Former users were defined as having used the drug for at least six consecutive months in the past but not within the last 30 days. Screening methods were used to validate eligibility, such as knowledge of the drug or an understanding of the local drug scene.

Interviews were conducted face-to-face in a safe but convenient place agreed upon by the interviewer and respondent, such as a private library room, the interviewer's car, or the respondent's place of residence. We obtained oral consent before collecting drug histories with paper and pencil, followed by an audio-recorded in-depth interview that further explored the details surrounding drug use, recovery, turning points, and social roles over the life course. The semi-structured, open-ended interviews were one to three hours long. Respondents received a $\$ 25$ reimbursement for their time at the end of the interview. No identifying material was collected that linked the data to the respondent. Our university's Institutional Review Board approved the study protocol, and a certificate of confidentiality was obtained from a federal agency that protected study interviewers and data from court subpoena. Interviews were conducted between July 2007 and December 2008.

\section{Sample demographics}

Our study sample of 100 included 50 active users of methamphetamine (used in the last 30 days), and 50 former users (did not use in the last 30 days). The demographics of the active and former users are shown in Table 1. The racial and gender distribution corresponds to reported demographics of methamphetamine users in rural areas of the southeastern U.S. (Sexton et al., 2008). The analysis for this article is on former user data. Among this sub-sample, $90 \%$ were white, $64 \%$ male, and $64 \%$ were 26 to 65 years old; the older respondents had a longer period of cessation.

The demographics of former users were similar to those of active users with a few exceptions. The active users included more minorities, and they started using methamphetamine at an older age than the former users. Both active and former users were polydrug users during the time of methamphetamine use, and both groups included respondents who reported re-occurring periods of methamphetamine use, cessation of use, and relapse events. We did not exclude respondents who 
used other drugs, because we were focused on problematic use, and all respondents reported problematic use of methamphetamine; additionally, our sample size would have been too small without them. However, we soon discovered that the inclusion of active polydrug users added additional insights that would have been lost if we had restricted the former group to those who ceased use of all drugs.

Table 1. Demographics of former users $(n=50)$ and active users

\begin{tabular}{|c|c|c|c|c|c|c|}
\hline $\begin{array}{l}\text { Demographic } \\
\text { characteristic }\end{array}$ & \multicolumn{3}{|c|}{ Former n (\%) } & Active $\mathrm{n}(\%)$ & & \\
\hline \multicolumn{7}{|l|}{ Gender } \\
\hline Male & \multicolumn{3}{|c|}{$32(64 \%)$} & $33(66 \%)$ & & \\
\hline Female & \multicolumn{3}{|c|}{$18(36 \%)$} & $17(34 \%)$ & & \\
\hline \multicolumn{7}{|l|}{ Race } \\
\hline White & \multicolumn{3}{|c|}{$45(90 \%)$} & $39(78 \%)$ & & \\
\hline $\begin{array}{c}\text { African } \\
\text { American }\end{array}$ & \multicolumn{3}{|l|}{$2(4 \%)$} & $9(18 \%)$ & & \\
\hline Hispanic & \multicolumn{3}{|l|}{$3(6 \%)$} & $2(4 \%)$ & & \\
\hline \multicolumn{7}{|l|}{ Age Group } \\
\hline $18-25$ & \multicolumn{3}{|c|}{$18(36 \%)$} & $13(26 \%)$ & & \\
\hline \multirow[t]{2}{*}{26 and older } & \multicolumn{3}{|c|}{$32(64 \%)$} & $37(74 \%)$ & & \\
\hline & Mean & $\mathrm{SD}$ & Range & Mean & SD & Range \\
\hline Age & 32.5 & 11.2 & $18-65$ & 36.4 & 11.7 & $19-56$ \\
\hline $\begin{array}{l}\text { Age first used } \\
\text { methampheta } \\
\text { mine }\end{array}$ & 20.4 & 6.1 & $12-38$ & 24.0 & 10.8 & $11-54$ \\
\hline
\end{tabular}




\begin{tabular}{|l|l|l|l|l|l|}
\hline $\begin{array}{l}\text { Age stopped } \\
\text { methampheta } \\
\text { mine }\end{array}$ & 30.4 & 10.6 & $16-53$ & \\
\hline
\end{tabular}

Table 2 shows the length of time for cessation of methamphetamine. Among the 50 respondents not using methamphetamine in the last month, three did not report an age when they stopped use. Of the 47 who reported a cessation age nearly $50 \%$ reported having ceased use for a year or less. Twelve percent ${ }^{2}$ reported to have ceased use for five years or longer and are considered to be in stable recovery. A description of those in stable recovery is added to the discussion to provide further supporting evidence for the concept of social recovery we introduce here.

Table 2. Length of cessation among former/former users* $(n=47)$

\begin{tabular}{|l|l|l|}
\hline Years since last use* & $\mathrm{n}$ & \% \\
\hline 0 & 9 & 19.1 \\
\hline 1 & 14 & 29.8 \\
\hline 2 & 9 & 19.1 \\
\hline 3 & 7 & 14.9 \\
\hline 4 & 2 & 4.3 \\
\hline 5 & 4 & 8.5 \\
\hline 9 & 1 & 2.1 \\
\hline 14 & 1 & 2.1 \\
\hline
\end{tabular}

\section{Data analysis}

The audio-recorded interviews were transcribed verbatim and entered into NVivo, a software program used for facilitating qualitative data analysis. To increase clarity of the complex processes of recovery, we triangulated the field observation notes, the drug history matrix, $\underline{3}$ and the transcribed interview data using an iterative model (Becker, 1998; Boeri, 2007). Inconsistencies found between data sources were clarified, validated or refuted in the ongoing data collection (Hansen, Maycock, \& Lower, 2001; Hunt, Joe-Laidler, \& Evans, 2002). 
Consistent with a modified grounded theory approach, we did not begin with an a priori hypothesis, although our analysis was informed by the literature on recovery discussed previously. For example, we found support for all routes to recovery in our initial analysis of the data and returned to the data repeatedly to discern the more subtle relationships and conceptual categories described by our respondents (Charmaz, 2001; Denzin \& Lincoln, 2000; Lofland, Snow, Anderson, \& Lofland, 2006; Strauss \& Corbin, 1998). This means that the extant definition of recovery (treatment programs, 12step programs and natural recovery) "earned its way into the analysis" and was not imposed (Charmaz, 2005, pp. 512-513).

Our working definition of recovery as cessation of problematic drug use indicated for some cessation of methamphetamine but not necessarily total abstinence of all substances. Incorporating respondents' viewpoints on pathways to recovery with those examined in the literature, we uncovered increased overlap, making it more difficult to distinguish routes to recovery from the various strategies employed. Challenged by the complexity of the data, we used visual tools such as Venn diagrams to organize and compare users' descriptions of recovery (Ragin, 2008). This led to deconstructing recovery processes to differentiate routes from strategies.

All respondents mentioned more than one route to recovery and most indicated multiple attempts. The three broadly defined types of recovery routes described in the literature above informed our choice for a first-level classification for all routes mentioned by our respondents. 4 The column headings on Table 3 indicate the routes: (1) formal treatment; (2) 12 step groups; and (3) natural recovery. In the formal treatment category, we combined institutionalized mandated treatment and noninstitutionalized (self-selected) treatment because our respondents conceptualized them as the same type of treatment route. This treatment category includes both inpatient and outpatient programs. The 12-step groups include Alcoholic Anonymous (AA), Crystal Meth Anonymous (CMA), Narcotics Anonymous (NA) and other group meetings using the self-help model. All recovery routes described by respondents that did not fit within the formal treatment or 12-step group models were classified under the rubric of natural recovery. These included any route that did not involve attending a meeting, therapy, or other formal/ informal structure designed for recovery purposes. We found that these three routes could be used in combination; for example, required attendance at a 12-step support group was typically employed within the formal treatment programs. Likewise, some respondents reported a natural route such as using another drug to replace use of methamphetamine, while simultaneously attending formal treatment or a 12-step meeting where the use of any other drug was prohibited or viewed as stigmatizing behavior. We classified respondents by the most recent route identified in their recovery story.

Table 3. Mentions of social recovery strategies by type of route to recovery* $(n=50)$ 


\begin{tabular}{|l|l|l|l|}
\hline Social recovery strategies & Treatment $(\mathrm{n}=38)$ & 12 -Step $(\mathrm{n}=35)$ & Natural recovery $(\mathrm{n}=36)$ \\
\hline Social support & 5 & 10 & 4 \\
\hline Goal focus & 3 & 4 & 3 \\
\hline Avoidance & 3 & 3 & 3 \\
\hline Spiritual experience & 1 & 3 & 6 \\
\hline Substitute drugs & 2 & 0 & 25 \\
\hline Total mentions & 14 & 20 & 3 \\
\hline
\end{tabular}

Note: * Multiple strategies mentioned by each respondent.

Strategies were coded here as any method, tool, behavior, action or other influence mentioned by a respondent that helped achieve cessation. The strategies used within each of the routes to recovery are shown in Table 3. We counted every mention of strategies used by every respondent regardless of which route (i.e., treatment, 12-step, natural recovery) was employed. The final list of strategies was categorized as: (1) social support; (2) goal-focus; (3) avoidance; (4) religious/spiritual experiences; and (5) using a substitute drug. Social support encompassed family, friends, counselors, healthcare providers, social workers, or even strangers. Goal-focus referred to specific actions taken to replace the methamphetamine-user role in the respondent's life. Avoidance (called the geographic cure in 12step literature) is used in many treatment programs as well as in natural recovery. This refers to avoiding the people and places that tempt one to use a drug or otherwise cause craving, often described as triggers. Religious or spiritual experiences include references to help from a higher power mentioned as instrumental for some respondents for recovery. Finally, the use of substitute drugs was a strategy employed in professional treatment, when legal drugs could be prescribed, but most often mentioned in natural recovery, when legal or illegal substances might substitute for the problematic drug. For example, problematic users who received medical attention for a psychiatric issue such as depression often referred to their medication as a substitute for illicit drugs which aided their recovery without formal drug treatment. However, users also referred to substituting a less problematic drug, such as marijuana, to help stop methamphetamine use.

We organize our findings by the first level categories of routes $(n=3)$ with the second level categories of strategies $(n=5)$ shown within each route. Since some quotes are better presented along with the interviewer's questions, an [I] indicates a question from the interviewer, where needed. We use nearly verbatim quotes but delete unnecessary conversational repetitions or terms, such as "like," "uh," and 
"you know," when they distract from the content addressed, and we use ellipses to indicate when superfluous words were omitted. Bracketed words are inserted to explain slang terms or to protect the anonymity of a person or specific place. The strategies are supported here by at least two quotes from different respondents. - Our aim is to provide quotes that best represent the recovery strategies described by more than one respondent in the sample; however, we acknowledge that even one deviant case is beneficial when constructing a new concept (Burawoy, 1998). $\underline{6}$ The inclusion of over 30 quotes within our route/strategy configuration offers ample evidence that many of the same strategies were employed across all routes. We reserve a more in-depth summary of all 15 combinations of strategies and routes for the discussion section where we expand on our parsimonious explanation of how the quotes presented in the findings contributed to our concept of social recovery.

\section{Findings}

Among the 50 former users, 38 mentioned formal treatment as a path to their recovery; 35 mentioned attending 12-step groups, and 36 mentioned routes other than these that were classified as natural recovery. ${ }^{7}$ Some strategies were discussed in terms of being used simultaneously with multiple routes or consecutively with two or more routes. Moreover, because of the overlap of different routes to recovery at the same times, such as attending a 12-step program while involved in formal treatment, quotes may represent more than one route. Not all strategies were discussed as a specific route to recovery, but instead they emerged in the discussion of the recovery career. Triangulating data sources helped us to establish which strategy was used at the time when it was most salient to the respondent's successful recovery.

\section{Formal treatment}

The respondents most likely to mention formal treatment programs were those who could afford the costs of private treatment, had relatives who could afford it, or had insurance that paid for treatment. Other respondents were mandated to attend treatment by parents, work, or legal authorities. While different programs might offer a variety of treatment aids, the 12-step model was often embedded within the treatment process, whether as a part of inpatient treatment or aftercare plan. In this section we present the quotes that describe strategies employed only in formal treatment models only.

\section{Social support}

Social support was not always recognized as a strategy but was revealed in the remarks made by respondents when talking about their recovery. For example, one 28 -year-old white male had been in three different treatment programs before he stopped problematic use of all drugs while in his fourth treatment facility, a Christian-based residential home. His description of his current position as an alumnus shows the social support he received was instrumental and provided him with an important social role: 
It's under [Religious] Church International. We just had our eighth anniversary for the Men's House [a residential treatment]. I'm one of the head ushers at Church International. I'm also the alumni director for the Men's House ministry. We have family recovery and I'm one of the group leaders. Yeah, it's all about getting plugged in somewhere.

In another example, a 19-year-old woman reported her methamphetamine use landed her in jail twice before her parents sought help from the police to enroll her in an expensive long-term treatment program, claiming she was suicidal. She reported: "I was in [Residential Program] where I met a lot of the people that I'm somewhat friends with today and all of a sudden I was on this pink cloud, like oh sobriety's so great." The eight-week long residential treatment program changed her perspectives and established enduring social bonds with other patients. In both cases, we see the importance of bonding with a social support group, a common theme among respondents in treatment.

\section{Goal-focus}

The 19-year-old woman mentioned in the last paragraph indicated that while in treatment she acquired the goal to stay sober after 7 years of progressively more problematic drug use:

I think at that point I was ready for a change. And I think it actually gave me the view on the sober years of my life, which until after 12 years old there wasn't any until rehab. I think they gave me the opportunity to mature ... and that's why I'm able to you know stay clean.

Our further analysis of her entire recovery trajectory revealed that having a goal (taking on adult roles and responsibilities) coincided with reducing or ceasing drug use, whether or not the goal was cessation. One 19-year-old male was signed into a treatment program he did not want to attend. While in treatment, he started a new job and began to show a desire to stop using methamphetamine:

Yeah, it was like hell for the first couple of months, and then I got on work release and I finally got to go out and work and make money. And it started easing me off of it more and more ... I have a baby on the way and I'm gonna get married ... and I work every day, seven days a week.

This young man described earning an income as the first goal that motivated him to stop using, and by the time of the interview he had acquired additional social roles that acted as barriers to relapse.

\section{Avoidance}

Counselors in the treatment programs often warned recovering users to avoid friends and places that would cause them to relapse, admonitions that were typically embraced by respondents in our sample. A 41-year-old white male who had been in and out of treatment programs and now lived in a 3/4 house (a residence shared by recovering users who often met while participating in a treatment program) described how he previously relapsed with recovering friends: 
We were just buddies in a program. When you're buddies you talk, you know.

[I] And they could tell that you wanted to get high too? Sure, I guess.

[I] So what happens now if that happens again? What are you going to do about that?

I'm going to try to run the other way ... I'm in a safe place right now, in a safe environment.

He continued to emphasize his desire to avoid old drug-using buddies at all costs.

In contrast, a 30-year-old white male recounted a different avoidance technique he used with his old, drug-using buddies: "I invite them to church. Yeah, that pretty much keeps them away." Here we see how his changed social relations and context influenced him to avoid his old social network.

\section{Religious/spiritual experience}

Of the respondents who received formal treatment while in a criminal justice program, most often it was through the drug court treatment model. Among our sample, drug court also included some kind of religious fellowship. According to the following 37-year-old white female, the treatment provided by drug court helped her recovery largely due to its spiritual dimension:

And I got the probation and all from the possession and the DUI charges. And I still got four years left on there. But I just moved down a level. They took me off intensive [treatment] last week and I've got a new probation officer, and I've done all my community service, and I've done everything I was supposed to do-all my programs, and all my treatment, and all my evaluations, and therapy and everything. And it's all helped, you know. But honestly the biggest thing is depending on God.

This respondent indicated the drug court treatment guided her recovery, but she gave the ultimate credit to her success in recovery to a higher power.

Similarly, a 28-year-old white male echoed what we heard from many of our respondents, "Well I guess I restored my relationship with my Lord ... It's more surrendering to God and he took over my life once again." While his spiritual conversion is a personal change, his access to this catalyst occurred in the social context of the drug court treatment.

\section{Substitute drug}

Many of the respondents we interviewed went to a detoxification unit (detox) in a medical facility before entering treatment. Here they were often provided prescription drugs to help ease withdrawal symptoms. For some, prescription drugs were used after leaving detox and going into treatment, such as the following 41-year-old white male recounted: 
I've been to detox I don't know how many different times. I could count in between, let's see, maybe seven times, six or seven times ... Laying there while throwing up. You know, I was high. I didn't want to be there. I was angry. I was depressed. ... That's when they started giving me, I think it's Zoloft they started me out on for depression and it got to the point where I don't guess it was working and the second or third time I went back they changed my medicines to what they called Effexor, and I take Effexor now to this day. I also take Trazodone at night to sleep. I do have a time with insomnia now. It's hard for me to sleep.

Depression had impacted this man's life long before he was clinically diagnosed and prescribed Effexor. The fact that he also was prescribed another prescription anti-depressant, Trazodone, to sleep shows that his depression might have been quite serious. Although he was in an outpatient treatment program, the pharmaceutical prescription for depression was a significant turning point in his recovery.

One 38-year-old Latina woman reported problematic use of poly-substances, including methamphetamine and heroin. Due to her heroin use, she was able to enter an outpatient treatment program that provided her with daily doses of methadone, which she claims was instrumental to her cessation of all drugs:

[I] You said recently you get urine tested. So is that a reason you don't use methamphetamine now?

The methadone clinic I go to-they get me all eight of my medications through a grant, through a government grant, and I pay for the price of my methadone, all my heart medicine and everything ... And now I get all eight of them and that included my methadone. So seven of them and then my methadone for twelve dollars a day, $\$ 84$ a week, under the agreement that I have clean methadone-only drug screens.

This woman became completely drug free when she subsequently was weaned off methadone through the dedicated counseling provided in this government-subsided treatment program.

\section{Step programs}

For the purpose of our study, a 12-step program refers to all forms of self-help groups using the steps outlined by Bill W. (Cheever, 2004). These include abstinence from all substances except for tobacco and caffeine. Twelve-step programs strongly encourage regular group meetings, daily for some treatment plans and at least weekly for most individuals in recovery. This often becomes a lifelong pursuit. 


\section{Social support}

The importance of the social aspects of groups cannot be over-emphasized; the buddy system or sponsor provide one-on-one help for an individual in recovery who is contemplating relapse. The dynamics and efficacy of each group will vary even within the same group over time. Respondents in our study frequently mentioned that this variance was dependent upon the composition of the members in specific 12-step groups. A 42-year-old white male who was already four years recovered from problematic drug use said that the 12-step group conversational setting was absolutely needed for recovery:

You have to be involved in a support network, like AA, NA, or CMA, some type of 12-step program, and be willing to work the steps in order to realize what your character defects are and the reason why you used and deal with the feelings - the feelings that cause you to use, such as feeling inadequate and less than and not a cop-out and needing to fit in.

As seen in this quote, the end result of attending a program was "fitting in" to a social network that understands and enables his discussion of recovery. This man's recovery story demonstrates the influence of the 12-step philosophy on his personal change.

Another respondent who lived in a 3/4 house that encouraged group meetings indicated that frequent and almost daily social support from his 12-step group was vital to his recovering success: "I go to meetings every night, except for Saturdays ... I am around people that are doing it-people who are going through the same program, quitting." Typically the need for like-minded companions is a philosophy delivered in a social group setting, indicating that the social supporting system inherent in a 12-step group reinforces the belief that a recovering user must continue to attend meetings.

\section{Goal-focus}

A common goal mentioned by many in a 12-step group was to become a peer sponsor or counselor to others. For example, one 26-year-old Latino male recounted a life of homelessness without goals until he maintained his current 12-step fellowship and found not only inspiration but also a reason to stay clean:

Being able to see other people and the 12-step programs, to have more than several years of living regular lives. And they have the same story that I do, that were shooting dope in the dope houses; they were destitute and homeless. That gives me hope that I can stop. Originally that's how I first got sober. Now it's me doing the flip side of that-of helping other people.

This participant's social support group became a motivator for his own cessation of use, and assisting others in their cessation also became a goal that kept him focused on not returning to drug use. On one 
level, it appears this person decided to change his life; however, the process included working within a group that defined an acceptable goal other than using drugs.

Being part of a 12-step group helped respondents to achieve their individually-defined goals as well, such as a 28 -year-old white male who said: "I had accomplished the goals I'd wanted to accomplish ... Have a car, have enough money to pay my rent a couple months ahead of time. I had a good core of people I talked to on a regular basis." Here, we see a common theme of one goal leading to another and the overlapping of multiple strategies. This man started with the goal of having a car and paying rent, and his support group helped him to stay focused on this goal and to achieve it.

\section{Avoidance}

Avoiding one's former drug-using friends was a strategy mentioned by all respondents who were in a 12-step group. One 27-year-old white woman described how she felt when seeing old friends:

They tell you in NA you've got to change your play places, play people, and play things ... I think the biggest problem that people have-I tried to get clean several times just because other people wanted me to and then I would see my old friends. I mean you have to get away from those people, even if it means pushing them away and being mean, if that's what it takes.

In this woman's story, we see that the social support she found in the 12-step group not only motivated her to avoid seeing her old friends but also helped her to shift her social horizon.

Similarly, a married man explained how his relapse was related to being around the wrong people: And you know, I thought before I could go back to smoking pot and drinking and you know never do the hard stuff, but it went okay for a little while like that, but I started being around the wrong people, wrong things, and I do the wrong things ... I can't drink. I can't smoke pot. I can't be around them kind of people.

[I] So it's not necessarily the drug that's pulling you?

It's the people. ... I mean I hate the drug. I know what's going to happen if I get around them people.

This middle-aged man used an avoidance strategy, but he was helped by his participation in 12-step.

\section{Religious/spiritual experience}

As can be expected, mention of a higher power was common among those who used a 12-step route to recovery, since the program is based on acknowledging the need for spiritual help. A 41-year-old white male encapsulated what many other respondents in 12-step also said: 
But you know, it's not so much the drugs or the being broke and going to jail and the losing girls. It's not so much those things as after having some extended period of recovery. It's where my head and my behavior goes when I stop pursuing the spiritual way of life. Once you get that little spiritual thing going, and you find out you're not in control of everything and that you rely on God for some things, things just get so much better.

Even the hardest cases said working the 12-steps helped them stop using, and God keeps them from relapsing, such as a 19-year old woman who had been living in hotels with methamphetamine dealers until she became homeless:

[I] You mentioned God earlier. Is that like a stronger influence in your life now?

Yea, it's about as strongest influence ... My idea of God is there's a God and He loves me a lot and He wants what's best for me. That's it. And he helps me stay clean.

Likewise, a 53-year-old male confirmed that it was the spiritual aspects of the 12-step program that helped him stop and stay off drugs:

You know the 12-step program -it has spirituality to it. I think AA, 12-step, NA, is really an addict's only hope.

[I] You can't do it on your own? You need a higher power?

Right, right. A higher power type mind set ... God had taken away my urge to drug and drink, almost totally.

Many similar descriptions of the influence of a higher power, offered by those who attended 12-step groups, confirmed that the 12-step route to recovery is closely intertwined with a spiritual experience.

\section{Substitute drug}

As mentioned, the 12-step model strictly discourages use of any drug or substance while "working the program" [following the steps to recovery]. Unlike formal treatment programs that prescribe drugs to help patients, some respondents participating in 12-step groups reported that they were asked to stop taking any prescribed drug that could be used recreationally, such as prescription drugs for depression or attention deficit disorder. No respondent in the 12-step recovery route mentioned using a legal or illegal drug as a substitute; yet, the majority smoked cigarettes and mentioned drinking more coffee after ceasing drug and alcohol use.

\section{Natural recovery}

All respondents tried multiple routes to recovery, and many had already attempted formal treatment and 12-step programs numerous times before ceasing problematic use on their own. At this point, we 
report the strategies used by the respondents in their most recent attempts at recovery that did not include treatment or participation in 12-step groups. Since this route is the most controversial, we provide more supporting data.

\section{Social support}

Many respondents attributed their recovery to being self-motivated, but upon closer examination that motivation came from various social factors such as friends or family. Analysis showed that social forces and social context were instrumental in the respondents' recovery processes. For example, one 23-year-old white male in his third year of successful recovery explained how he stopped problematic use by staying at the house of an older friend:

Her house was a haven for lost children ... It was a one-bedroom apartment, and I lived in the living room for about nine months because she knew that I needed somewhere to be. I was unemployed during the nine months that I went clean. I quit my job at Waffle House, and I essentially locked myself in the apartment. I left the apartment to go grocery shopping, to go see a movie, or something like that. But for the most part, I became incredibly anti-social, and I put myself through all of my withdrawals. Getting off of meth was really hard physically. I woke up sick every day for six months.

While claiming to be anti-social, this man described a close relationship with someone who offered a place to live and social support while he recovered from years of problematic methamphetamine use.

The significance of relationships was also described by a 27-year-old female who stated, "I can't speak for anybody else's reasons, but I'm back in school. I have a family that's supportive of me. I'm married." A supportive filial and spousal relationship helped this woman reach a turning point toward her recovery, a process that led to a change in her social context and a new identity formed by relationships with others. In another example, a 22-year-old female indicated close social support from her mother:

And so I called my mom and I was like, "Will you please come get me?" And she said, "Only if you're completely done with those people and everything." And so I moved back home, and I stayed with her like twenty-four hours a day. That's basically when I stopped.

In this woman's story, we see that reinvigorating one's relations to those not associated with problematic use can be a strategy employed for a successful recovery without the need for formal treatment or a 12-step fellowship. The round-the-clock support of her mother and a reinvestment in a significant parental relationship led to a shift in the respondent's social horizon, which in turn aided her social recovery and cessation of drug use. While this women was able to obtain help from a family member, others whose family relationships were unhealthy or unavailable found help from 
relationships outside the family. Another young female in the study stated that her boyfriend's support of her recovery efforts led her to participate in drug-free activities that were critical to her success:

He [boyfriend] is just a completely positive character. He would just calm me down a lot of times. And he had, like, more of a life. Instead of waking up every day, like, how am I going to get high today-his was, you know, let's go do this, let's go do that. It was more of, like, activity was a way of trying not to think about it. He was taking me everywhere. We'd go to [Resort Beach]; we'd go to [Resort Lake], everywhere.

Her example also illustrates the importance of promoting new social activities and ways of social interrelating as key aspects of successful recovery.

\section{Goal-focus}

Respondents using natural recovery often mentioned acquiring new goals and becoming focused on those goals as tools of a natural recovery. Three consistent types of goals mentioned by our respondents included keeping or acquiring gainful employment, completing higher education, and participating in volunteer work. Even though several respondents reported formerly using methamphetamine at work, they also indicated that a renewed focus on occupational goals was a primary route to recovery without treatment. Often a combination of goals was mentioned. One 26year-old white male said his fear of losing his wife motivated him to start his migration to recovery, but it was the work environment that helped him migrate successfully to a non-user identity:

Really, my wife gave me a talk. She was about to leave, you know, and I really just had my son then, and I didn't want to lose my family. I figured if I lost my family it's really just going to go. It was at the point where I was hitting rock bottom, but I figured if I lost my family, there'd be no way of coming back up. So it's kind of my final chance to get away from this. And I drank a little bit-after the crack, I drank and smoked weed. I smoked weed for a little bit until I finally quit that, and that kind of just kept me away from it-and just spent more time with the family. Got a job working during the day and changed my atmosphere ... my paycheck went straight to my wife, so there was no hiding money anymore.

Because the respondent focused on one goal (to maintain his position as a member of his family) and used other strategies (i.e., moderate use of other drugs), he eventually was able to accomplish his successful cessation of problematic use.

For some of the younger respondents, the social environment of school provided a goal that motivated them to achieve a natural recovery. One 19-year-old white female, who had started methamphetamine use at age 15, had been incarcerated a few times before she developed a new goal of achieving a college education: "I have no intention of ever using meth again ... I'm going to school full time, I've got a 
boyfriend, and I work part time." Like others, this respondent described various strategies that led to new social roles, all of which were incongruent with the role of a problematic drug user.

\section{Avoidance}

In natural recovery, avoidance refers to the conscious decision made by a user to avoid the settings and people associated with methamphetamine use rather than being coerced to do so by probation or by formal and informal treatment requirements. As one 48-year-old white male explained:

You know, if I'm not around it, I'm not going to go looking for it anymore. The only hard thing about it is if I'm around it. I see somebody hitting on a pipe, it will create a Jones [craving] and I got to get up and get the devil out of there because if I don't, I know I'm going to eventually try to rationalize it away in my mind where I can do it a little ... If I get around it, it's too much of a temptation. Usually seeing it, visually seeing it is the hardest. You know, seeing somebody doing it is harder than talking about it. Talking about it don't really create any cravings. But if you're around people doing it, it does tend to make you want to do it.

Similarly, a 21-year-old female suggested that to stop using, one needed to avoid old drug-using contacts at all costs:

I think that the only way that you can stop yourself-I mean obviously I'm a very strong-minded person because I just stopped cold turkey and most people cannot do that. But I think the only way that anybody could get away from it is either getting caught or moving far away where you don't know anybody.

Both of these respondents insisted that avoiding other users was necessary; however, not all were so socially selective. One 23-year-old white female reported: "I kind of just stopped hanging out with that whole crowd for a long time. I only hang out with one of the girls that I used to do it with, but I don't do it with her now." Her recovery strategy indicates that in contrast to the strict avoidance of all drug users required by treatment and 12-step group participation and often considered necessary by those attempting natural recovery, a range of avoidance levels based on personal decisions and selfdiscipline can also be successful.

\section{Religious/spiritual experience}

The turning point toward drug cessation for some in natural recovery was a religious or spiritual experience. A 43-year-old white male stated that it was a chance encounter during his attempted suicide that prompted a religious turn, and through this he was able to find the strength to cease all drug use five years ago. Deeply addicted to methamphetamine and having attempted several unsuccessful attempts to stop, he was preparing to commit suicide at a secluded construction site when two men approached him looking for work. The happenstance of meeting these two men in a 
deserted construction site late at night led the respondent to leave the site and contact an acquaintance affiliated with the church. The respondent said that on the way to his friend, he was "praying and believing, and I pulled up, and this train came by and I asked God to put all my pain and sickness on that train and it was like it left me." He cried at this point in the interview, indicating an ongoing, deep, emotional experience that still affected him after five years.

In another example, a 33-year-old white male who had quit methamphetamine on his own attributed his current faith in himself to his religious beliefs:

[I] How are you able to, without any treatment ... how are you able to just kick it?

I think it partly goes back to my religion. I believed more in myself and I don't look for a higher power to give me strength. I look to myself for strength. And when I see myself being weak, you know, people see their god being weak, they start losing faith. It's generally the reason why they do lose faith. So if you're viewing yourself as your god, you don't want to see your god weak so you've got to make yourself strong.

Based on his religious training, this man replaced a belief in a higher power God with himself as a god although this would not be considered a traditional religious experience. Seeing himself as a god who is strong gave him faith in his own ability to stop his problematic use of a drug.

\section{Substitute drug}

Substituting another drug for problematic methamphetamine use was the most controversial strategy we discovered in the analysis of our respondents' stories of recovery. Some reported using illegal substitute drugs while others used prescription drugs obtained legally or illegally as strategies in a natural recovery route. The most common drug mentioned as a substitute drug was marijuana. A few claimed that without marijuana they never could have ceased use of methamphetamine or maintained recovery. "In a lot of ways that was my sanity," said a 23-year-old white male who was now three years in successful recovery from methamphetamine use. Likewise, a 19-year-old male explained why he used marijuana:

It makes my stomach turn whenever I even think about it [methamphetamine use]. Like just because everything about it has always, the outcome is always bad-no matter what. But with marijuana, it's like, it makes days better ... It's momentarily ... It's a way to forget the past I guess.

Other respondents used legal substances such as tobacco or alcohol on their route to recovery.

According to some respondents, alcohol and other drugs helped them to stop methamphetamine without leading to addiction to the substitute drug. The following illustrates one case in which the recovery process involved the use of alcohol: 
I went to AA after rehab, and I did that whole deal for a while, and then I fell out of it because the same thing anyone falls out of anything-you just don't care anymore. And it's not to say that I went back out [relapsed], although eventually I did start drinking occasionally. It was more along the lines - to stay clean from meth.

The 21-year-old white man's occasional drinking resulted in leaving the 12-step program. Yet, he did not view this as problematic since his primary concern was to cease use of methamphetamine. On his own, he stopped using methamphetamine through a natural recovery route. At the time of the interview, he had not used methamphetamine for two years. He also was attending college and controlling his drinking patterns.

\section{Stable recovery}

While not part of our original aims, we include a brief overview of those in stable recovery to lend further support for a social recovery conceptual framework. Stratifying recovering persons according to length of remission supports cessation efforts while at the same time providing new, drug-free goals for the recovery-minded individual (Chen, 2006). Six respondents in our study were former users in stable recovery, which is defined as not having used methamphetamine for the past five years or more (Cloud \& Granfield, 2001). Table 4 depicts the characteristics of this group by single cases. Since our study focused on the cessation of methamphetamine, the continued use of tobacco, alcohol, marijuana and other drugs in the past month are shown in this table. The former users in stable recovery included both male and female, ages range from 23 to 65. In our sample, only white former users reported stable recovery from methamphetamine use; however, consistent with national rates, whites also represent the majority of methamphetamine users (SAMHSA, 2008). Three of those in stable recovery continued to drink alcohol, three used marijuana, two used other drugs occasionally, and two stopped all use of illicit drugs. All but one smoked cigarettes daily, which is a licit substance but increasingly stigmatized in society. Having a history of injecting drugs is a barrier to cessation; only one of the respondents in stable recovery ever injected drugs. This is the respondent who used crack in the last month, which he indicated in his interview was a one-time event that he did not intend to repeat. The only other respondent to use an illegal drug other than marijuana was a woman who used prescription pills occasionally. All considered themselves to be in healthy and stable social relationships with family and friends, and none were actively involved in a drug-using network. The trajectories of those in stable recovery provide further insights into the migration process involved in social recovery (Boeri, Harbry, \& Gibson, 2009). For some, as indicated previously, a sudden cessation of all substances resulted in frequent relapse, but a slower process that started with stopping problematic drug use allowed them to acquire the social capital needed for stable recovery.

Table 4. Stable recovery* by years of cessation and other substance use in last month $(n=6)$ 


\begin{tabular}{|l|l|l|l|l|l|l|l|l|}
\hline ID & Age & $\begin{array}{l}\text { Years in } \\
\text { Cessation }\end{array}$ & Gender & Tobacco & Alcohol & Marijuana & Other & $\begin{array}{l}\text { Ever } \\
\text { injected }\end{array}$ \\
\hline$\# 12$ & 23 & 5 & Female & Yes & Yes & Yes & No & No \\
\hline$\# 30$ & 44 & 9 & Male & Yes & No & Yes & No & No \\
\hline$\# 40$ & 48 & 5 & Male & No & Yes & No & Crack & Yes \\
\hline$\# 46$ & 43 & 5 & Male & Yes & No & No & No & No \\
\hline$\# 57$ & 22 & 5 & Female & Yes & Yes & Yes & Pills & No \\
\hline$\# 75$ & 65 & 14 & Male & Yes & No & No & No & No \\
\hline
\end{tabular}

Note: * Did not use methamphetamine for at least 5 years.

\section{Summary and discussion}

In this article, we explored routes to recovery from the perspectives of individuals who self-identified as former methamphetamine users. We employed a harm reduction definition of recovery as cessation of problematic drug use (Reinman, 2005; Reinarman, 2009). Our aim was to provide a phenomenological understanding of recovery routes (Adams, 2008). We also responded to calls for recovery research that take into account the diversity of recovery experiences and different social contexts in which drug events take place (Hoffmann, 2003).

In summary, the complex recovery patterns described by respondents in our study were shown here as configurations of routes and strategies. Routes are the pathways employed to stop using the problematic drug, while strategies are the means or tools employed along these routes. Although former users may have strong beliefs regarding which recovery routes worked for them, and often they generalize their own successful routes or strategies as required for stopping drug use successfully, the data show that no route should be ignored when seeking recovery. Beyond the wellstudied routes of formal treatment and 12-step groups, we found that natural recovery routes were also successful. Moreover, we identified five types of common strategies employed across all routes reported by our respondents: social support, goal-focus, avoidance, spiritual experiences, and substitute drugs. Each of these may be used in conjunction with formal treatment or 12-step programs as well as in a natural recovery route.

Each route to recovery has its own advantages and disadvantages. Formal treatment is advantageous because it often provides experienced staff and professional help from counselors and medical 
doctors, which is beneficial for those whose drug use is linked to mental health issues. The disadvantages include the inaccessibility of formal treatment for many due to prohibitive costs. The advantages of 12-step include its anonymity and cost-free participation, as well as its accessibility. The recovery meetings themselves are an alternative to drug use, and the social network of 12-step groups provides the recovery-minded individual social support when beset by cravings (Kelly et al., 2008). However, as previous research shows, 12-step groups are not conducive for all those who seek help for their substance use problems (Peele, Bufe, \& Brodsky, 2000). Participation in a 12-step group can limit one's range of social networking opportunities considerably, although this (ideally) is a short-term effect of entering the program. The advantages of natural recovery include the cost-free participation, learning how to use alcohol or drugs in moderation, and not necessarily having to leave one's entire social network. One significant disadvantage of natural recovery is that it is recognized as a route to recovery by only a limited number of professionals and is certainly not an option in conventional recovery environments, although strategies for natural recovery have historical representation in the literature (Biernacki, 1986; Granfield \& Cloud, 2001; Reinarman \& Levine, 1997; Sobell, 2007).

Addressing the broadest base of issues within the range of problematic drug use is necessary to help the greatest number of people in their recovery effort (Klingemann \& Klingemann, 2007). By focusing our phenomenological analysis on all strategies employed in all routes to recovery, social strategies emerged to be most salient. Among the five strategies used, four had social dimensions that were used in all routes to recovery. Our findings add to the literature on the irreducibly social nature of drug use and underscore the need to more fully engage the social environment with recovery discourse (Hughes, 2007; Klingemann, 2011).

Contemporarily, recovery is seen as an historical marker to highlight the shift in the user's behavior and living practices. Our analysis shows that all recovery models also involved a shift in identity within a social context, since identity is intimately involved with our place in society and our interaction and relations within community (Bailey, 2005). Becoming part of conventional society has been shown to be beneficial for former drug users as well as the formerly incarcerated (Cantora, 2013; Klingemann, 2011). People define themselves by their relationships to their social environments, so the migration from a drug user role within a drug-using social context to a more conventional role in society is needed. Kathryn Hughes (2007) describes this process as identity migration, a conceptual understanding that illuminates the fundamentally relational nature of strategies used on the route to recovery (Boshears et al., 2011). Our exploration of the identity migration process of those shown to be in stable recovery highlights this point.

Six respondents in our study were in stable recovery. All reached the turning point into this status as a result of natural recovery strategies, but they also used multiple routes and strategies along the way. Four had been in some type of treatment during their recovery trajectory, but not immediately before 
they started the road to stable recovery. Two respondents mentioned prior participation in a 12-step group had helped them in their previous recovery efforts. Five mentioned a family member or partner helped in the recovery process, three reported new goals as an aid to recovery, three revealed they avoided their former drug-using networks, and two used a substitute drug to help them in the process. All revealed a process that encompassed the identity migration model. For example, one man's recovery path included formal treatment and 12-step participation before he had a religious conversion. For this man, more than the mere presence of a drug-free social network was necessary. He indicated that increasing his set of fulfilling roles and stronger social bonds were needed to incite and reward his progress throughout his long recovery career. His in-depth interview data also revealed that pursuing his goal as a responsible father and participating in his church changed his relations to his social environment and enabled his identity migration to a successful stable recovery status.

One strategy of natural recovery deemed most controversial was the use of an illicit drug to help relieve withdrawal symptoms or use of a substitute drug or substance considered less harmful (McBride et al., 1997; Reinman, 2009). While we do not necessarily condone this strategy, the fact that many in stable recovery not only used another substance but also continued to use an illicit drug merits further attention. Non-problematic drug or alcohol use appeared to help avoid relapsing into problematic use of methamphetamine. Those in stable recovery indicated a controlled or modulated use of other substances. No one in stable recovery used alcohol daily. Most who smoked marijuana used only occasionally, and the one person who used crack in the last month smoked it only once when with a friend who used. The only respondent in stable recovery who used marijuana daily reported that she was also using prescription pills she obtained legally due to medically diagnosed problems, and she used marijuana to counteract the negative effects of prescription pills. Notably, only two respondents in stable recovery fit the model of total abstinence of all substances.

It is easy to blame a unique individual for being weak in the face of a constant barrage of drug use, but years of attempting to end a drug pandemic through formal treatment and incarceration or isolating recovering users in selected self-help groups has shown that more options are needed. We propose that conceptualizing recovery as social recovery captures the diversity of social influences and social strategies used in all recovery routes; moreover, doing so does not repudiate any of the current models that are working well for some.

The major limitation of this study is that it cannot be generalized beyond the research sample. Our conclusions are limited in scope due to the small sample size and restricted by type of drug use identified as problematic. We make no claim on the generalizability of our findings; yet, small qualitative studies add important insights that can inform future large-scale studies (Denzin \& Lincoln, 2000; Lofland et al., 2006; Mitchell et al., 2011; Pach \& Gorman, 2002; Rhodes \& Moore, 2001). 
Lack of follow-up data collection to establish a more robust assumption of non-problematic use of methamphetamine is another limitation. As discussed earlier, one month, one year, or even five years of cessation does not indicate that problematic use has ended forever. Future studies should address these limitations using a longitudinal design and larger random samples to test hypotheses that may be drawn using social recovery as a dependent variable. Future research also is needed to explore the concept of social recovery among problematic use of drugs other than methamphetamine, as well as how social recovery might be impacted by the severity of drug use.

In conclusion, we propose that conceptualizing recovery as social recovery allows the strategies identified here to gain more research and professional attention. We posit that incorporating the concept of social recovery within treatment vernacular could aid those seeking cessation of problematic drug use but who have a difficult time ceasing all use of drugs and alcohol. Our definition of social recovery refers to the process of acquiring the skills, resources, and networks needed that enhance people's ability to live in society without resorting to problematic substance use. As a process, social recovery focuses on ameliorating the social aspects of problematic drug use through social relations with non-users and social roles that increase social capital. This article contributes to a growing body of literature that emphasizes the social nature of both drug use and addiction (Adams, 2008; Davies, 1998; Graham et al., 2008; Hammersley \& Reid, 2002; Hughes, 2007; Klingemann, 2011; Lindesmith, 1938; May, 2001; Pilkington, 2007). If people wavering between drug use and sobriety were given access to more strategies for social recovery, it could reduce the number of attempts at sobriety, and, therefore, relieve the public burden of institutionalized treatment centers and the overpopulation of incarcerated drug users.

\section{References}

Adams, P.L. (2008). Fragmented intimacy: Addiction in a social world. New York, NY: Springer.

Akers, R. L. (1991). Addiction: The troublesome concept. The Journal of Drug Issues, 21, 777-794.

Alcoholic Anonymous. [1952] (1981). The twelve steps and twelve traditions. New York, NY: Alcoholics Anonymous World Services.

Bailey, L. (2005). Control and desire: The issue of identity in popular discourses of addiction. Addiction Research and Theory, 13, 535-543.

Barker, J.C. \& Hunt, G. (2007). Natural recovery: A cross-cultural perspective. In H. Klingemann, \& L.C. Sobell (Eds.) Promoting SelfChange From Addictive Behaviors: Practical Implications For Policy, Prevention, And Treatment. New York, NY: Springer.

Barrick, C. \& Connors, G.J. (2002). Relapse prevention and maintaining abstinence in older adults with alcohol-use disorders. Drugs Aging, 19, 583-594. 
Barton, G.R.; Hodgekins, J.; Mugford, M.; Jones, P.B.; Croudace, T., \& Fowler, D. (2009). Cognitive behavior therapy for improving social recovery in psychosis: Cost-effectiveness analysis. Schizophrenia Research, 112, 158-163.

Becker, H.S. (1998). Tricks of the trade: How to think about your research while you're doing it. Chicago, IL: University of Chicago Press.

Belenko, S. (1999). Research on drug courts: A critical review. National Drug Court Institute Review, 1, 144.

Biernacki, P. (1986). Pathways from heroin addiction: Recovery without treatment. Philadelphia: Temple University Press.

Bischof, G.; Rumpf, H.J.; Meyer, C.; Hapke, U. \& Ulrich, J. (2007). Stability of subtypes of natural recovery from alcohol dependence after two years. Addiction, 102, 904-908.

Bletzer, K.v. (2009). Modulation of drug use in southern farming communities: Social origins of polyuse. Human Organization, 68, 340-349.

Boeri, M.W. (2007). A third model of triangulation: Continuing the dialogue with Rhineberger, Hartmann and van valey. Journal of Applied Social Science, 1, 44-50.

Boeri, M.W. (2013). Women on ice: Methamphetamine use among suburban women. New Brunswick, NJ: Rutgers University Press.

Boeri, M. W.; Harbry, L. \& Gibson D. (2009). A qualitative exploration of trajectories among suburban users of methamphetamine. Journal of ethnographic \& Qualitative Research, 3, 139-151.

Boeri, M.W.; Lamonica, A. K. \& Harbry, L. (2011). Social recovery, social capital, and drug courts. Practicing Anthropology, 33, 8-13.

Boshears, P.; Boeri, M. \& Harbry, L. (2011). Addiction and sociality: Perspectives from methamphetamine users in suburban USA. Addiction Research \& Theory, 19, 289-301.

Bourdieu, P. (1984). Distinction: A Social critique of the judgment of taste. Cambridge, MA: Harvard University Press.

Burawoy, M. (1998). The extended case method. Sociological Theory, 16, 4-33.

Cantora, A. (2013). Building grounds for release: Women's perceptions of a community corrections program. Journal of Qualitative Criminal Justice and Criminology, 1, 197-220. 
Charmaz, K. (2001). Grounded theory. In: R.M. Emerson (Ed.), Contemporary Field Research: Perspectives and Formulations. Prospect Heights, IL: Waveland Press.

Charmaz, Kathy (2005). Grounded theory in the 21st century. In The SAGE Handbook of Qualitative Research, N. K. Denzin and Y. S. Linclon (Eds). (3rd ed.) Thousand Oaks, CA: Sage Publications.

Cheever, S. (2004). My name is Bill W.: Bill Wilson, his life and the creation of alcoholics anonymous. New York, NY: Washington Square Press.

Chen, G. (2006). Natural recovery from drug and alcohol addiction among Israeli prisoners. Journal of Offender Rehabilitation, 43, 1-17.

Cheung, Y.W. \& Cheung, N.W.T. (2003). Social capital and the risk level of post-treatment drug use: Implications for harm reduction among male treated addicts in Hong Kong. Addiction Research $\mathcal{B}$ Theory, 11, 145-162.

Cloud, W. \& Granfield, R. (2001). Natural recovery from substance dependency: Lessons for treatment providers. Journal of Social Work Practice in the Addictions, 1, 83-104.

Cloud, W. \& Granfield, R. (2008). Conceptualizing recovery capital: Expansions of a theoretical construct. Substance Use \& Misuse, 4, 1971-1986.

Coleman, J.S. (1988). Social capital in the creation of human capital. American Journal of Sociology, 94, S95-S120.

Davies, J.B. (1998). Pharmacology versus social process: competing or complementary views on the nature of addiction? Pharmacology and Therapeutics, 80, 265-275.

Denzin, N. \& Lincoln, Y. (2000). Handbook of qualitative research (2nd ed.). Thousand Oaks, CA: Sage.

Deschenes E., Ireland, C. \& Kleinpeter, C. (2009). Enhancing drug court success. Journal of Offender Rehabilitation, 48, 19-36.

Dole, V.P. \& Nyswander, M.E. (1965). A medical treatment for diacetylmorphine (heroin) addiction. Journal of the American Medical Association, 193, 646-650.

Emrick, C., Tonigan, J., Montgomery, H. \& Little, L. (1993). Alcoholics anonymous: What is currently known? In McCrady, B. \& Miller (Eds.) Research on alcoholics anonymous: Opportunities and alternatives. New Brunswick, NJ, Rutgers Center of Alcohol Studies.

Fischer, B.; Rehm, J., Kim, G. \& Kirst, M. (2005). Eyes wide shut: A conceptual and empirical critique of methadone maintenance treatment. european Addiction Research, 11, 1-14. 
Gorman, M.E., Morgan, P. \& Lambert, E.Y. (1995). Qualitative research considerations and other issues in the study of methamphetamine use among men who have sex with other men. In: E. Lambert; R. Ashery \& R. Needle. Qualitative methods in drug abuse and HIV research, NIDA Research Monograph, 157 NIH Publication No. 954025. Washington, DC: US Government.

Graham, M. D., Young, R.A., valach, L. \& Wood, R.A. (2008). Addiction as a complex social process: An action theoretical perspective. Addiction Research \& Theory, 16, 121-133.

Granfield, R. (2004). Addiction and modernity: A comment on a global theory of addiction. Nordic Studies on Alcohol and Drugs, 44, 27-32.

Granfield, R \& Cloud, W. (1996). The elephant that no one sees: Natural recovery among middle-class addicts. The Journal of Drug Issues, 26, 45-61.

Granfield, R. \& Cloud, W. (1999). Coming clean: Overcoming addiction without treatment. New York, NY: New York University Press.

Granfield, R. \& Cloud, W. (2001). Social context and natural recovery: The role of social capital in the resolution of drug-associated problems. Substance Use E Misuse, 36, 1543-1570.

Grant, S., St. John, W. \& Patterson, E. (2009). Recovery from total hip replacement surgery: “It's not just physical." Qualitative Health Research, 19, 1612-1620.

Hammersley, R. \& Reid, M. (2002). Why the pervasive addiction myth is still believed. Addiction Research \& Theory, 10, 7-30.

Hansen, D., Maycock, B. \& Lower, T. (2001). “Weddings. Parties, Anything ...": A qualitative analysis of ecstasy use in Perth, Western Australia. International Journal of Drug Policy, 12, 181-199.

Hoffmann, H.C. (2003). Recovery careers of people in alcoholics anonymous: Moral careers revisited. Contemporary Drug Problems, 30(3), 647-683.

Hubbard, R.L., Flynn, P. M., Craddock, S.G. \& Fletcher, B.W. (2001). Relapse after drug abuse treatment. In: F. M. Tims; C. G. Leukefeld \& J. J. Platt (Eds.), Relapse and recovery in addictions. New Haven, CT: Yale University Press.

Hughes, K. (2007). Migrating identities: The relational constitution of drug use and addiction. Sociology of Health \& Illness, 29, 673-691.

Hunt, G.P, Joe-Laidler, K. \& Evans, K. (2002). The meaning and gendered culture of getting high: Gang girls and drug use issues. Contemporary Drug Problems, 29, 375-415. 
Kaufman, S. \& Poulin, J. (1996). Coherency among substance abuse models. Journal of Sociology and Social Welfare, 23, 163-174.

Kelly, J.F., Brown, S.A., Abrantes, A., Kahler, C.W. \& Myers, M. (2008). Social recovery model: An 8 -year investigation of adolescent 12-step group involvement following inpatient treatment. Alcohol Clin exp Res, 32, 1468-1478.

Klingemann, J. (2011). Lay and professional concepts of alcohol dependence in the process of recovery from addiction among treated and non-treated individuals in Poland: A qualitative study. Addiction Research \& Theory, 19, 266-275.

Klingemann, H. \& Klingemann, J. (2007). Hostile and favorable societal climates for self-change: Some lessons for policymakers. In: H. Klingemann \& L.C. Sobell (Eds.) Promoting self-change from addictive behaviors: Practical implications for policy, prevention, and treatment. New York, NY: Springer.

Kunishio K, Matsumoto Y, Kawada S, Miyoshi Y, Matsuhisa T, Moriyama E, Norikane H, Tanaka R. (1993). Neuropsychological outcome and social recovery of head-injured patients. Neurol Med Chir (Tokyo), 33, 824-829.

Lamonica, A. \& Boeri, M. (2012). An exploration of the relationship between the use of methamphetamine and prescription drugs. Journal of ethnographic $\mathcal{E}$ Qualitative Research, 6, 160-174.

Laudet, A. B. (2007). What does recovery mean to you? Lessons from the recovery experience for research and practice. Journal of Substance Abuse Treatment, 33, 243-256.

Laudet, A. B. (2008). The road to recovery: Where are we going and how do we get there? Empiricallydriven conclusions and future directions for service development and research. Substance Use $\mathcal{E}$ Misuse, 43, 2001-2020.

Laudet, A.B. \& White, W.L. (2008). Recovery capital as prospective predictor of sustained recovery, life satisfaction, and stress among former poly-substance users. Substance Use $\mathcal{E}$ Misuse, 43, 27-54.

Lindesmith, A. (1938). A sociological theory of drug addiction. American Journal of Sociology, 43, 593-613.

Lofland, J.; Snow, D.; Anderson, L. \& Lofland, L.H. (2006). Analyzing social settings: A guide to qualitative observation and analysis. Belmont, CA: Thomson Wadsworth.

Logan, B. (2002). Methamphetamine effects on human performance and behaviors. Forensic Science Review, 14, 133-151.

Lyons, T. (2010). Recovery capital, drug policy, and the cycle of incarceration. Practicing Anthropology $32,41-44$. 
May, C. (2001). Pathology, identity, and the social construction of alcohol dependence. Sociology, 35, 385401.

McBride, A. J., Sullivan, G., Blewett, A.E. \& Morgan, S. (1997). Amphetamine prescribing as a harm reduction measure: A preliminary study. Addiction Research, 5, 95-112.

Mitchell, S.G., Morioka, R., Reisinger, H.S., Peterson, J.A., Kelly, S.M., Agar, M.H., Brown, B.S., O'Grady, K.E. \& Schwartz, R.P. (2011). Redefining retention: Recovery from the patient's perspective. Journal of Psychoactive Drugs, 43, 99-107.

Moore, D. (2005). Enabling environments and the reduction of drug-related harm: Re-framing the Australian policy and practice. Drug and Alcohol Review, 24, 275-284.

National Institute on Drug Abuse (NIDA). (2006). Community epidemiology work group:

Epidemiological trends in drug abuse (advance report). NIH Publication U.S. Department of Health and Human Services. No. 06-5878.

National Institute on Drug Abuse (NIDA). (2009). Principles of drug addiction: A resource-based guide. NIH Publication No. 09-4180. Washington, DC: US Government Printing Office.

Nolan, J. L. Jr. (2003). Reinventing justice: The American drug court movement. Princeton, NJ: Princeton University Press.

Pach III, A. \& Gorman, E.M. (2002). An ethno-epidemiological approach for the multi-site study of emerging drug abuse trends: the spread of methamphetamine in the United States of America. Bulletin on Narcotics, 54, 87-102.

Peele, S. (1989). The disease of America: Addiction treatment out of control. Lexington, MA, Lexington Books.

Peele, S., Bufe, C. \& Brodsky, A. (2000). Resisting 12-Step coercion: How to fight forced participation in AA, NA orl2-step treatment. Tucson, Az: Sharpe.

Pilkington, H. (2007). In good company: Risk, security, and choice in young people's drug decisions. Sociological Review, 55, 373-392.

Pollner, M. \& Stein, J. (1996). Narrative mapping of social worlds: The voice of experience in Alcoholics Anonymous. Symbolic Interaction, 19, 203-223.

Putnam, R.D. (2000). Bowling alone: The collapse and revival of American community. New York, NY: Simon and Schuster. 
Ragin, C. (2008). Redesigning social inquiry: Fuzzy sets and beyond. Chicago, IL: University of Chicago Press.

Reinarman, C. (2005). Addiction as accomplishment: The discursive construction of disease. Addiction Research \& Theory, 13, 307-320.

Reinarman, C. \& Levine, H. (1997). Crack in context: Demon drugs and social justice. Berkeley, CA: University of California Press.

Reinman, A. (2009). Cannabis as a substitute for alcohol and other drugs. Harm Reduction Journal, 6, 635.

Rhodes, Tim \& Moore, D. (2001). On the qualitative in drug research: Part one. Addiction Research \& Theory 9, 279-97.

Ross, J. I. \& Richards, S. C. (2002). Behind bars: Surviving prison. New York, NY: Penguin Group.

Ross, J. I. \& Richards, S. C. (2009). Beyond bars: Rejoining society after prison. New York, NY: Penguin Group.

Schuller, T. (2007). Reflections of the use of social capital. Review of Social economy, 65, 11-28.

Scott, C.K., Foss, M.A. \& Dennis, M.L. (2005). Pathways in the relapsetreatment-recovery cycle over 3 years. Journal of Substance Abuse Treatment, 28, S63-72.

Sexton, R.L., Carlson, R.G., Leukefeld, C.G. \& Booth, B.M. (2008). Barriers to formal drug abuse treatment in the rural south: A preliminary ethnographic assessment. Journal of Psychoactive Drugs, 40, 121-129.

Sobell, L.C. (2007). The phenomenon of self-change: Overview and key issues. In H. Klingemann \& L.C. Sobell (Eds.) Promoting self-change from addictive behaviors: Practical implications for policy, prevention, and treatment. New York, NY: Springer.

Stewart, D.G. \& Brown, S.A. (1995). Withdrawal and dependency symptoms among adolescent alcohol and drug abusers. Addiction, 90, 627-635.

Strauss, A. \& Corbin, J. (1998). Basics of qualitative research: Techniques and procedures for developing grounded theory (2nd ed.) Thousand Oaks, CA: Sage.

Substance Abuse and Mental Health Services Administration (SAMHSA). (2008). Results from the 2007 National Household Survey on Drug Use and Health: National Findings, CESAR FAX 17: 39. 
Waldorf, D. (1983). Natural recovery from opiate addiction: Some socialpsychological processes of untreated recovery. Journal of Drug Issues, 13, 237-280.

Watters, J. \& Biernacki, P. (1989). Targeted sampling: Options for the study of hidden populations. Social Problems, 36, 416-430.

Weinberg, D. (2000). Out there: The ecology of addiction in drug abuse treatment discourse. Social Problems, 47, 606-621.

Weinberg, D. (2005). Of others inside: Insanity, addiction, and belonging in America. Philadelphia, PA: Temple University Press.

\section{Contributors}

Miriam Boeri received her $\mathrm{PhD}$ in Sociology from Georgia State University. As a research associate at Emory University she conducted ethnographic research among drug users. While Associate Professor at Kennesaw State University, she received funding from the National Institute on Drug Abuse to continue her research. She has numerous scholarly publications on drug use including a book on suburban women who use methamphetamine. Her findings add to our understanding of how to reduce the adverse social impact of drug use, such as incarceration, poverty and unemployment. She is currently conducting research on medical marijuana in Massachusetts and teaches at Bentley University.

David Paul Gibson Jr. is an undergraduate medical sociology student at Kennesaw State University. He has experience conducting ethnographic fieldwork and collecting in-depth interviews and drug use histories. His analyses of quantitative and qualitative data on drug users and their social environments led to co-authored research articles published in the Journal of Ethnographic and Qualitative Research and the International Journal of Drug Policy.

Paul Boshears is Co-Editor of the journal continent. and a PhD candidate (advisor Avital Ronell) at the European Graduate School in Switzerland where he has studied with Giorgio Agamben, Judith Butler, Jacques Rancière, and Slavoj Žižek. Paul's dissertation is concerned with drug addiction as a mode of technological relating and explores the therapeutic potential classical Chinese philosophies present. His research and studies have been conducted in East Asia, West Africa, Europe, and North America. Paul's work has appeared in scholarly journals across diverse disciplines including Addiction Research \& Theory, Comparative Continental Philosophy, and the American Journal of Bioethics-Neurosciecnce.

\section{Acknowledgement}

This research was supported by NIDA grant 1R15DA021164-01A1 (Miriam Boeri, PI). The views presented in this article are those of the authors and do not represent those of the funding agency. We 
would like to thank the participants in this study for sharing their stories of recovery and the anonymous reviewers for their thoughtful insights.

\section{Footnotes}

1. Although these terms are used interchangeably, here we employ the term natural recovery instead of self-change to avoid a focus on the individual that might be easily confounded with self-help processes commonly used in 12-step groups.

2. We include the percentages for each demographic variable, years since last use, and strategy mentioned in each route to recovery in the tables, with the acknowledgement that as a qualitative analysis these are descriptive of the sample only and do not imply a statistical difference. $\doteq$

3. The drug history data were entered into a SPSS software program and used here for descriptive purposes. The varibales used include race and ethnicity (self-defined); age, age of first use of every drug, and age when drug use ceased (for each drug when applicable). Six recovery routes were identified, coded and counted during qualitative analysis. No statistical analysis of these routes has been conducted. $\doteq$

4. We note that distinguishing route from strategy was not an a priori methodological decision but instead emerged from the qualitative data analysis. Once the distinctions were made, we looked to the literature for published examples of routes and strategies. We found support primarily for routes not distinguished by strategies. $\leftrightarrows$

5. We do not claim that specific quotes we chose are fully representative of the recovery strategies. As a qualitative study, there are nuances in every quote that make it unique, but we found similarities that allowed us to organize the strategies mentioned in our study into identifiable patterns and categories. $\doteq$

6. Michael Burawoy (1998) made the argument that even one deviant case increases the empirical content of theory reconstruction. Likewise, we propose that in our small sample, even one mention of a recovery strategy provides empirical support for a reconstructed conceptualization of recovery.

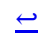

7. We remind readers that many respondents mentioned multiple routes to recovery. Since we are not conducting a statistical analysis of these routes and allowed respondents to choose more than one route, the percentages do not equal $100 \%$ and are not reported here. $\bullet$ 